\title{
Analysis on Teaching Practice Adaptive to Art and Design Courses of Local Colleges
}

\author{
Xiaoyan Ge \\ Academy of Fine Arts \\ Huanggang Normal University \\ Huanggang, China 438000
}

\begin{abstract}
According to the current situation of art and design major in local colleges, the adaptive teaching methods of art and design courses are proposed. Teaching contents suitable for students' learning level are designed on the basis of students' characteristics and development requirements. Students should be guided to propose, analyze and solve problems with their wisdom. Local colleges should use interdisciplinary advantages and characteristics of regional development to meet the requirements of social development. Different teaching methods are used in practical teaching to improve students' ability in self decision and independent analysis.
\end{abstract}

\section{Keywords — art and design courses; adaptive teaching}

\section{COURSE PROVISION ADAPTS TO STUDENTS CHARACTERISTICS AND DEVELOPMENT}

Art and design education emphasizes individualized teaching on practice basis. At present, the training of students changes from simple and complicated design to in-depth design. The tools are simple first and become more and more complicated. The design is increasingly mature. Students have improvements after four years of learning if they are aspirant. Colleges should train students' thoughts and the ability to think and learn. Students' present performance and previous performance should be compared to judge their academic progress. Students build confidence in the comparison and develop further. The characteristics of students in design major require teachers to have corresponding individualized teaching pattern.

In order to respect students' characteristics and personality, teachers should teach them in accordance to their aptitude. Firstly, the selection of topics should furthest stimulate students' learning initiative; secondly, teachers should encourage students to explore and give them constructive suggestions and space to think; thirdly, help students to find the best answer. Therefore, students are brave to express their opinions, have stronger consciousness of self-respect and become more interested in the topics, taking the initiative to seek answers for the questions.

Teaching case: In the professional basic course of Composition, the task is the composition of point, line and plan. Students are required to find materials from nature and life. It breaks through the traditional teaching pattern that focuses on technique teaching and professional learning. Course provision is to enlighten students and arouse their interests in experiencing the rich nature and life from different perspectives. Course design makes students feel pleasant and interested in life and arouses their learning enthusiasm. They learn to absorb the quintessence and develop the ability of independent learning and thinking, becoming "individualized" and "independent". Meanwhile, students' ability in innovative thinking is also expanded.

\section{USE INTERDISCIPLINARY ADVANTAGES AND REGIONAL DEVELOPMENT CHARACTERISTICS OF LOCAL COLLEGES TO MEET THE REQUIREMENTS OF SOCIAL DEVELOPMENT}

As a comprehensive interdisciplinary subject, the art and design major is to train students to acquire the ability of design innovation in solving problems. At present, the design education in China pursues practical teaching because it is a necessary teaching method in design major. Teachers of design major shouldn't "work behind closed doors". Instead, they should make the best of interdisciplinary advantages and regional development characteristics of local colleges, in order to meet the requirements of social development.

Firstly, although the class hour of professional courses in art education is inadequate and the professional ability is poor, the exchange between colleges and the provision of elective courses like sociology, marketing and philosophy greatly improve students' integrated quality and further promote the professional teaching. Secondly, economic society in which the colleges locate provides good and convenient practical environment for students. Schools can cooperate with local enterprises or companies and let students directly participate in design practice. Meanwhile, local regional culture lays solid foundation for art and design education. Teachers in art education should base on regional culture and integrate traditional culture in teaching. Students should be trained to have value orientation and cultural concept with local features. Therefore, teachers had better properly design tasks that can reflect geographic advantages, furthest reasonably use regional resources, in order to serve local economic society and benefit the students.

Teaching case: in the professional course of Package Design, students are asked to know about local cultural features and be guided to visit local museum and folklore museum, in order to collect, analyze and research related materials, extract modeling elements to design the package of 
products with local features. In the design and creation, students have keen interests in local culture and create actively. It gets rid of the previous situation that students are at a loss in design because of the hollow topics. The quality of design works improves obviously and have practical value.

\section{VARIOUS TEACHING Methods ARE APPliED to SPECIFIC TEACHING}

The traditional design education pays attention to accumulation of knowledge from one point to another point. Students' learning are passive acceptance. The teaching contents only focus on the authority of subject knowledge and neglect dynamic elements in teaching, students' experience in learning activities, interaction of teachers and students as well as the influence of potential course teaching. Therefore, students fail to achieve mastery through a comprehensive study of the subject. The knowledge cannot leave a deep impression on them. So they cannot apply knowledge comprehensively. The adaptive learning trains students to learn actively. Their ability of self decision and independent analysis are trained. Students take the initiative to absorb and learn instead of accept passively.

The process of adaptive teaching: we often proceed with teaching, learning and evaluation. Teachers teach, students digest and complete homework and then teachers evaluate. The teaching method adaptive to students' characteristics should integrate teaching, learning and evaluation. Students are trained to learn actively and grasp the ability of self decision and independent analysis. Educators change from passive teaching of knowledge and experience to active knowledge guidance, integration and innovation. For example, in course training, first, teachers require students to evaluate course contents and state their creation intention and design idea, analyze gain and loss in design and encourage them to innovate; second, let students give comments on each other and choose good assignments through vote and give reasons. It can promote students to learn from each other; lastly, teachers give conclusion for students' self-evaluation and mutual evaluation according to purpose and requirements of course training. Students are guided and enlightened in the whole process. They are interested in proposing, thinking and solving problems. It changes students' passive learning and train their correct design thinking and ability of design practice in a relaxed and natural learning atmosphere.

\section{CONCLUSION}

Adaptive teaching is first proposed by an American educationalist Gagne. In the Principle of Instructional Design, he addresses "the adaptive teaching refers to constantly monitor students' progress and change materials of teaching contents and management system accordingly". It is a teaching method provided for learners with great differences in achievement motivation, aptitude, learning style and previous experience to reach the common teaching objective. It requires to dynamically organize and present contents suitable for students' learning level and to adopt changeable teaching strategies in practical teaching according to students' ability and demands.

\section{REFERENCES}

[1] Yin Dingbang. Introduction to Design [M], Hunan Science and Technology Press, 2001

[2] Peng Jixiang. Introduction to Art [M], Higher Education Press, 2002

[3] Lin Jiayang. Design Innovation and Education [M], SDX Joint Publishing Company, 2002

[4] Chen Hanmin. Prospects for Art and Design Education [M], Southwest Normal University Press, 2007

[5] Pan Lusheng. Discussion on Design and Art Education [M], Shandong Pictorial Publishing House, 2005

[6] Ling Jiyao. Fifteen Chapters on the Artistic Designing [M], Peking University Press, 2006

[7] Research on Design Education, Nanjing University of the Arts, 2004, the first, second, third and fourth issues. 